\title{
Method of structural functional-value modeling of a complex system with a mixed combination of subsystems
}

\author{
Korobchynskyi M. ${ }^{1}$, Slonov M. ${ }^{1}$, Maryliv O. ${ }^{1}$, Lysenko S. ${ }^{1}$, Lehominova S. ${ }^{2}$, Lytvynska S. ${ }^{3}$ \\ ${ }^{1}$ Military-Diplomatic Academy named after Eugene Bereznyak, \\ 81 Y. Il'enka Str., 04050, Kyiv, Ukraine \\ ${ }^{2}$ State University of Telecommunications, \\ 7 Solomenska Str., 03680, Kyiv, Ukraine \\ ${ }^{3}$ National aviation university, \\ 1 Komarova Ave., 02000, Kyiv, Ukraine
}

(Received 15 September 2020; Revised 5 March 2021; Accepted 6 March 2021)

\begin{abstract}
The improved method of structural functional-value analysis of a complex system with a mixed combination of subsystems in an analytical approximation of the value dependences on the level of functional suitability is proposed. The minimization of the value of a complex system under the condition it fulfills its functional purpose at a given level is proposed to be implemented by the method of Lagrange multipliers. The application of the developed method allows checking the possibility of the monitoring system to perform its functional tasks with a given level of perfection as well as the identification of the opportunities for structural and parametric simplification of the system. This method is adapted for use at different levels of a priori uncertainty of the input data and can be useful at all stages of a complex system existence: development, operation, and disposal. In addition, it can be used to study low formalized and informalized complex systems.
\end{abstract}

Keywords: complex systems, perfection of a complex system, approximating functions.

2010 MSC: 49K10, 91B32

DOI: $10.23939 / \mathrm{mmc} 2021.02 .215$

\section{Introduction}

A complex system is a controlled system which combined machines and groups of people [1]. According to another definition, it is a controlled system, which is set of interconnected controlled subsystems that are united by a common purpose [2]. Complex systems are characterized by a large number of components, internal and external connections and their diversity.

According to the definition [2], the structural feature of a complex system is the presence of several subsystems. Subsystems and their relationships determine the content of the problem of studying a complex system. Each subsystem is characterized by parameters and properties.

The input of a complex system receives a number of signals (products) interaction of which in the subsystems will provide the output signal (product). The proximity of the output signals (products) of a complex system to a given level indicates the level of efficiency of its operation. The level of efficiency of a complex system is controlled by parameters and properties of subsystems and their structural organization.

Another characteristic feature of a complex system is the insufficiency of information for its effective management. This is determined by the large number of factors influencing the initial product of a complex system or insufficiency of analytical algorithms for the interaction of parameters and properties of subsystems. As a result, when modeling complex systems it's impossible to take into account all the factors that will affect its operation. Identification of rational approaches in the organization of complex systems is the subject of research in systems engineering and operations research. The results of such research are aimed at forecasting the necessary human, material, technological and financial resources for the rational functioning of a complex system. 
A variant of engineering research is functional-value analysis. Two generalizing factors are considered in the functional-value analysis. This is the degree of generic indicator of the functional perfection of a complex system $P_{\Sigma}$ and the total value of its operation $C_{\Sigma}$.

Today functional-value analysis is a common tool for working with complex systems at all stages of their existence: development, operation and disposal [3-16]. It aims to find a rational structure of a complex system. With such a structure, the implementation of a given level of functionality of a complex system will be achieved at a minimal spending.

Several approaches to functional-value analysis have been developed. The semantic approach is based on statistical generalization of data on the practice of existence of similar complex systems $[3,4]$. The possibilities of this approach are limited by the general recommendations for the implementation of parametric control of the efficiency of a complex system.

Approaches based on methods of interval probabilistic efficiency estimates have been diversified [5, 6]. Their branching is determined by the physical heterogeneity of the subsystems of a complex system. The dependence of properties and parameters on stochastic influencing factors is taken into account [5]. A promising area for improving such methods is the possibility of conducting research in conditions of uncertainty. The Dempster-Shafer method is involved in [7]. Such methods do not used algorithmic relationship between the value of a complex system and its functional perfection.

Impossibility of analytical and algorithmic formalization of the functioning of complex systems has led to the spread of expert methods for their evaluation $[8,9]$. Such methods allow solving the problems which can not have the algorithmic description. Also they allow making a description of the operation of a complex system. But the algorithmic correspondence between the level of functional perfection and the value of a complex system is not obvious.

The same applies to methods that use neural algorithms. They are adapted to the operation of powerful computing networks $[10,11]$. Even in this case, the relationship between the "parametersvalue" of a complex system is not considered in analytical form.

One of the directions of functional-value analysis of a complex system is the application of approximating dependences of the value of its subsystems on the level of their functional perfection. In this approach, the rationalization rule will look like this [1]:

$$
\left\{\begin{array}{l}
P_{\Sigma}=P\left[C_{i}\right] \geqslant P_{s} \\
C=\sum_{i=1}^{n} C_{i} \rightarrow \min
\end{array}\right.
$$

where $P\left[C_{i}\right]$ is the functionality that shows the dependence of the system on the task from the invested in it; $P_{s}$ is a set point of functional excellence; $C_{i}$ are the additives of value of its individual subsystems; $n$ is the number of subsystems.

Note that the number of subsystems $n$ can be considered not only the subsystems themselves, but also the connections between them. In addition, the development, operation and disposal of subsystems can also be considered as separate subsystems of a complex system. If $\Psi(n, l)$ is a function of the value of $l$ connections between parts of the system and operating values, then according to (1):

$$
C=\sum_{j=1}^{n} C_{j}+\Psi(n, l)=\sum_{j=1}^{n} C_{j}+\Psi_{1}(l)+\Psi_{2}(n+l),
$$

where $\Psi_{1}(l)$ and $\Psi_{2}(l+n)$ are functions of connection values and operating values.

If the combination is considered as separate links and taking into account (2) the value of the system (1) will be:

$$
C_{\Sigma}=\sum_{j=1}^{l} C_{j}+\sum_{j=1}^{n} C_{j}+a \sum_{j=1}^{l+n} C_{j}=\sum_{j=1}^{l+n} C_{j}+a \sum_{j=1}^{l+n} C_{j}=(1+a) \sum_{j=1}^{l+n} C_{j},
$$

where $a$ is the average proportionality factor. 
Thus, (1)-(3) is a functional-value model of the rational structure of a complex system. Its generalized form is:

$$
\left\{\begin{array}{l}
P_{\Sigma}=P_{\Sigma}\left\{P_{j}\right\} \geqslant P_{s}, \\
C_{\Sigma}=(1+a) \sum_{j=1}^{l+n} C_{j} .
\end{array}\right.
$$

To solve the system (4), it is necessary that the functions $P_{\Sigma}$ and $C_{j}$ be analytically given and fully adequate to the physical, social or other processes that accompany the existence of a complex system. But the expressions for such equations can not always be obtained due to the ambiguity or complexity of the formalization of such dependencies. Therefore, the general indicator of the functional perfection of a complex system is considered to be the probability $P_{\Sigma}$ of performing the problem. The generalized criterion of functional perfection of the whole complex system will be determined by the combination $P_{j}$.

If the probabilities $P_{j}$ are independent, then the first equation of the system (4) by sequentially performing the components of a complex system of their functional purposes will be:

$$
P_{\Sigma}=\prod_{j=1}^{l+n} P_{j}
$$

where $(l+n)$ is the total number of subsystems.

At parallel connection of functionally equally directed subsystems we have:

$$
P_{\Sigma}=1-\prod_{j=1}^{l+n}\left(1-P_{j}\right) .
$$

Equations (5) and (6) confirm that the perfection of a complex system depends on the quality of subsystems and their organization into a complex system.

In addition, the probabilistic estimate $P_{j}$ of the level of perfection of the subsystem allows proceeding its parametric description. The description of the whole complex system becomes parametric. For a significant number of subsystems, the dependences for $P_{j}$ are defined. An example is the equation for the probability $P_{j, 0}$ of detecting an object by its static image in complex systems of observation [12]:

$$
P_{j, 0}=\exp \left[-\left(\frac{B \dot{m}}{2 L R \sqrt{\Delta D}}\right)^{2}\right],
$$

where $B$ is the shape factor of the recognition feature with the linear size $L$ and the tonal contrast $\Delta D$ between object and background; $R$ is a resolution of the image with denominator of scale $m$.

In (7) the directions of parametric increase $P_{j, 0}$ are indicated. Thus, image resolution and tonal contrast must be increased. To do this, increase the pixel format of image storage, select the modes and parameters of the receiver according to the contrasting characteristics of the object, background, conditions of observation. The denominator of the scale $\dot{m}$ must be reduced, that is choosing a means of observation with a larger focal length or reduces the distance.

\section{Statement of the problem and basic equations}

In [13-15], there is proposed a method of structural functional-value modeling of a complex system with polynomial approximation. The method is based on the assumption of the relationship between value and functional excellence of a complex system. They are its competing and contradictory properties [1]. When choosing the type of approximation dependence take into account the following restrictions and 
conditions:

$$
\left\{\begin{array}{l}
C(P) \geqslant 0, \\
P_{1}>P_{2} \rightarrow C\left(P_{1}\right) \geqslant C\left(P_{2}\right), \\
\lim _{P \rightarrow 0} C(P)=0 \\
\lim _{P \rightarrow 1} C(P)=\infty .
\end{array}\right.
$$

The analytical limitations and conditions given in (8) are a consequence of the expediency and possibility of physical realization of a complex system. Requirements (8) satisfy exponential, logarithmic and polynomial dependences of the following types:

$$
\begin{aligned}
C_{j}(P) & =A_{j} P \exp \left(\frac{B_{j}}{1-P}\right), \\
C_{j}(P) & =\frac{A_{j} P^{B_{j}}}{\ln \left(\frac{1}{P}\right)} \\
C_{j}(P) & =\frac{A_{j} P}{1-P}
\end{aligned}
$$

where $A_{j}$ and $B_{j}$ are constants that can be selected empirically, statistically or analytically.

When choosing an approximating expression, it is necessary to focus on the intensity of the change in the value of the subsystem together with the change in the level of its functional perfection. It will be important not only had a chosen typed of ratio, but also the range of changes in the probability $P$, within which the system is studied. Two constants in relations (9) and (10) allow more accurate description of real physical dependencies.

The coefficient $A_{j}$ has a dimension of value. It characterizes the value that the customer can still pay for the functional purpose of the subsystem. The coefficient $B_{j}$ characterizes the intensity of approaching the value of the system the maximum value at $P_{j} \rightarrow 1$. The choice of a specific ratio depends on the desired accuracy of calculations and the availability of a priori data on analogues. For example, in the presence of data on the growth of the functional suitability of the subsystem-analogue on $\Delta P$ with increasing its value by $\Delta C$, the coefficient $A_{j}$ in (11) will be:

$$
A=\frac{\Delta C(1-P)(1-P-\Delta P)}{\Delta P}
$$

In [13], there are developed general algorithms for structural functional-value modeling of a complex system with polynomial approximation of the dependence of the value of subsystems. But the features of this approach were considered only for complex systems with sequential connection of individual subsystems. In [14], there is given an example of application of algorithms developed in [13]. Article [15] extends the possibilities of functional-value modeling of a complex system in polynomial approximation of the dependence of the value of subsystems on the level of functional perfection.

When using the approximations (11) and (12), the functional-value model (4) of the rational structure of a complex system with a sequential connection of subsystems will take the following form (excluding operating spending):

$$
\left\{\begin{array}{l}
P_{\Sigma}=\prod_{j=1}^{m} P_{j} \geqslant P_{s} \\
C_{\Sigma}\left(P_{j}\right)=\sum_{j=1}^{m}\left(\frac{A_{j} P_{j}}{1-P_{j}}\right)=\min _{0 \leqslant P_{j} \leqslant 1} .
\end{array}\right.
$$

For complex systems with parallel connection of subsystems of the same functional orientation, it will be:

$$
\left\{\begin{array}{l}
P_{\Sigma}=1-\prod_{j=1}^{m}\left(1-P_{j}\right) \geqslant P_{s}, \\
C_{\Sigma}\left(P_{j}\right)=\sum_{j=1}^{m}\left(\frac{A_{j} P_{j}}{1-P_{j}}\right)=\min _{0 \leqslant P_{j} \leqslant 1} .
\end{array}\right.
$$


However, many complex systems are characterized by mixed, i.e., both parallel and serial, connections of individual subsystems. Problem of using this method to study such complex systems remain unresolved. Thus, the purpose of research is to improve the method functional-value analysis of a complex system with a mixed combination of subsystems with analytical approximation of the dependence of their value on the level of functional excellence.

To achieve the purpose of the study, the following tasks were set:

- to formulate initial data for calculations and structure of equivalent schemes of functional-value analysis of complex systems with mixed combination of subsystems;

- to find out the application of the developed algorithms of functional-value modeling of a complex system with a mixed combination of subsystems.

Consider the procedure for solving them. For the successful implementation of the tasks of functional-value analysis requires functional and structural information about the complex system. It is contained in the definition of the functional purpose of each subsystem and its structural connections with other subsystems. Such information will allow building the general structural scheme. In such a scheme, not all structural connections between individual links exist in a clearly expressed form. It is necessary to build an equivalent scheme, where these issues are solved by introducing conditionally existing additional links. The approach to the structure of the equivalent functional-value structural scheme will be considered on the example of the system shown in Fig. 1.

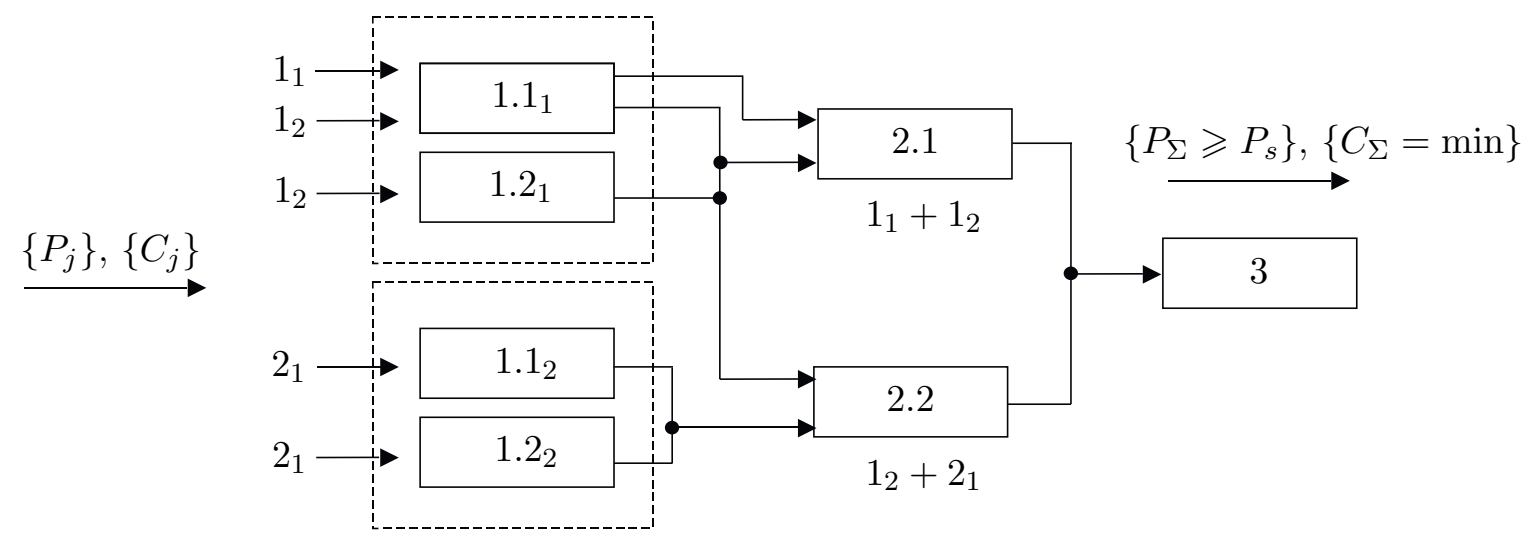

Fig. 1. Block scheme of a complex system of two groups of sensors.

According to Fig. 1 there are two groups of primary information sensors. The first group includes two sensors (subsystems for measuring or retrieving information). The first sensor measures the values of two parameters: $1_{1}$ and $1_{2}$. The second sensor performs a parallel measurement of parameter $1_{2}$ in order to increase the level of functional perfection of the system to determine this parameter. The second group also includes two sensors that measure parameter $2_{1}$.

The output signals from the sensors are fed to two processing links (processing subsystems). The first link is specialized for processing the output signals according to parameters $1_{1}$ and $1_{2}$. The second link is specialized for processing the output signals according to parameters $1_{2}$ and $2_{1}$. Its input receives signals from both the first group of sensors and from the second. The output signals from the processing links are fed to the generalization link.

Thus, in the given scheme the parallel measurement of parameter $1_{2}$ in both sensors of the first group are provided. Parallel and independent processing of this parameter is carried out in processing units 1 and 2. This increases the functional perfection of a complex system for measuring parameter $1_{2}$, as well as processing the measurement results.

The operation of links $1.1_{1}, 2.1$ and 2.2 simultaneously on two parameters leads to ambiguity in determining the magnitude that characterize their value and probabilistic properties for each of the parameters: $P_{11.1}, C_{11.1}, P_{2.1}, C_{2.1}, P_{2.2}$ and $C_{2.2}$. To remove such ambiguity it is necessary to 
conditionally divide the components of the schemes that are responsible for more than one action (measurement, processing and generalization) into conditional components (conditional subsystems) each of which is responsible for only one action. Such a scheme would be equivalent. Each component has only one input and one output.

In an equivalent circuit the first sensor of the first group is conventionally divided into two independent links (sensors). One of them measures the parameter $1_{1}$, the second is $1_{2}$. Each of them is described by the values of perfection $P_{111.1}, P_{112.1}$ and the value of $C_{111.1}, C_{112.1}$. Also $\left(C_{111.1}+C_{112.1}\right)=C_{11.1}$, $P_{111.1}$ and $P_{112.1}$ are estimates of the functional excellence of the first sensor according to parameters $1_{1}$ and $1_{2}$, Fig. 2 .

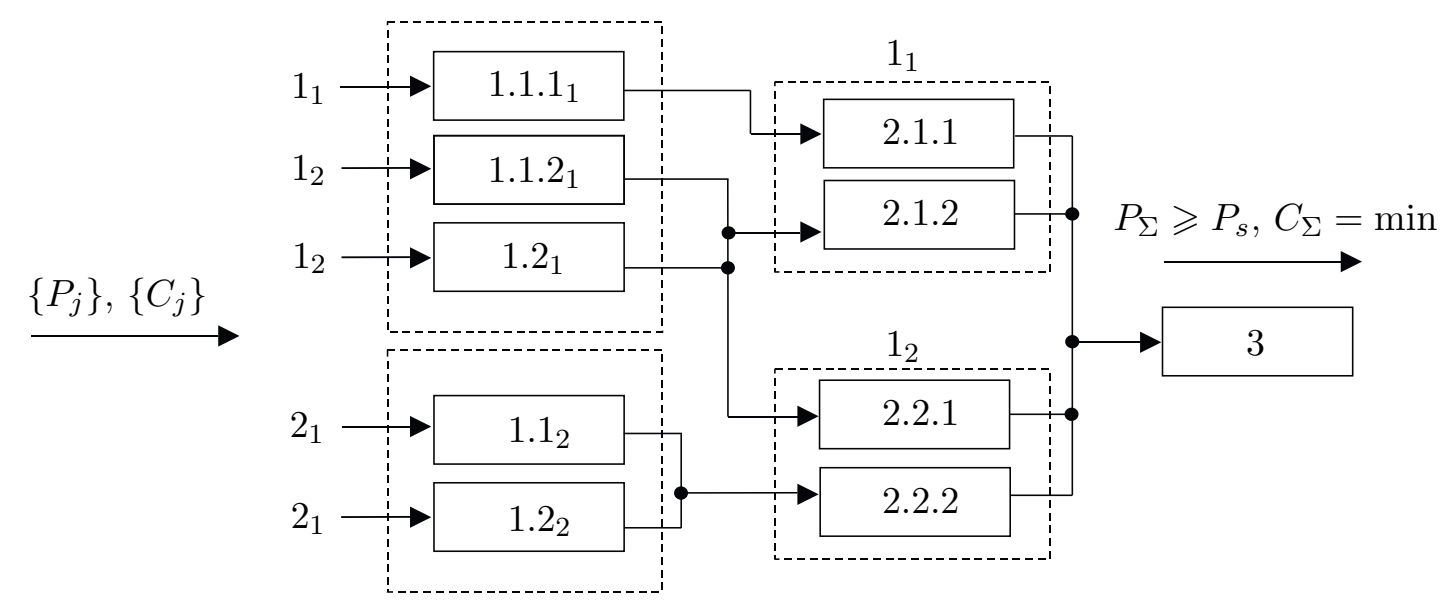

Fig. 2. Equivalent functional-value structural scheme of a complex system of two groups of sensors.

The same operation must be performed on the processing links. Each link is conditionally divided into two. The first link is divided into links for processing the measurement results of parameters $1_{1}$ and $1_{2}$. The second link is divided into links for processing the measurement results $1_{2}$ and $2_{1}$.

The results of the transformations presented in Fig. 2 , and according to $(5,6,12,13)$, allow presenting a system of equations of value rationalization in the following form:

$$
\left\{\begin{aligned}
P_{111.1} & {\left[1-\left(1-P_{112.1}\right)\left(1-P_{12.1}\right)\right]\left[1-\left(1-P_{11.2}\right)\left(1-P_{12.2}\right)\right] P_{21.1} } \\
& \times\left[1-\left(1-P_{21.2}\right)\left(1-P_{22.1}\right)\right] P_{22.2} P_{3}=P_{s}, \\
C_{\Sigma}= & \sum_{j=1}^{5} C_{D j}+\sum_{j=1}^{4} C_{o k}+C_{y}=\left(\sum_{i=1}^{2} C_{1.1 . i}+C_{1.2 .1}+\sum_{j=1}^{2} C_{1 . j}\right) \\
& +\left(\sum_{l=1}^{2} C_{2.1 . l}+\sum_{m=1}^{2} C_{2.2 . m}\right)+C_{3}=\min .
\end{aligned}\right.
$$

Equation (15) can already be used to rationalize the construction of a complex system, which is shown in Fig. 1. In this case, the specified level of functional excellence $P_{s}$ behind the entire system is achieved with minimal value. They do not decrease for individual sensors, processing subsystems or parts of generalization but they decrease for the whole system under analysis. The solution of equations of functional-value analysis of a complex system is based on the application of the Lagrange multiplier method $[15,16]$. An iterative approach is used for equations above the third order [15].

Substituting in (15) approximating expressions for $C(P)$ type (11) makes sense only after the construction of equivalent schemes and writing for them the corresponding expressions of rationalization. The peculiarity of the analysis in this case will be that the different physical content of the functioning of individual parts of the system may lead to the feasibility of using different approximating dependencies (9), (10) and (11). 
The structure of matrices (tables) can help to carry out the analysis of a complex system. An example of constructing a table of structural correspondence of the system is given in Table 1 . The table presents data on the links of three levels: sensor links $\left(P_{\text {sen }}, C_{\text {sen }}\right)$, processing links $\left(P_{\text {proc }}, C_{\text {proc }}\right)$, generalization links $\left(P_{g e n}, C_{g e n}\right)$. This table will help to avoid confusion after increasing the number of value and functional excellence in the equivalent scheme.

Table 1. Structural correspondence of system components from two groups of sensors.

\begin{tabular}{|c|c|c|c|c|c|c|c|}
\hline Number of links & $P_{\text {sen }}$ & $P_{\text {proc }}$ & $P_{\text {gen }}$ & Number of links & $C_{\text {sen }}$ & $C_{\text {proc }}$ & $C_{\text {gen }}$ \\
\hline 1 & $P_{111.1}$ & $P_{21.1}$ & $P_{3}$ & 1 & $C_{111.1}$ & $C_{21.1}$ & $C_{3}$ \\
\hline 2 & $P_{112.1}$ & $P_{21.2}$ & - & 2 & $C_{111.2}$ & $C_{21.2}$ & - \\
\hline 3 & $P_{12.1}$ & $P_{22.1}$ & - & 3 & $C_{12.1}$ & $C_{22.1}$ & - \\
\hline 4 & $P_{11.2}$ & $P_{22.2}$ & - & 4 & $C_{11.2}$ & $C_{22.2}$ & - \\
\hline 5 & $P_{12.2}$ & - & - & 5 & $C_{12.2}$ & - & - \\
\hline
\end{tabular}

For each combination of values $\{C\}$ and $\{P\}$ can be compiled their own tables of structural correspondence. A complete list of possible values of such combinations is all possible variants of the structure of a complex system. The task of analysis is to choose the most value-effective version of its structure.

Features of the use of functional-value analysis of a complex system with a mixed combination of subsystems will be considered on the example of a monitoring system, Fig. 3. It ensures timely receipt of the required amount of reliable information about the monitored object. The task is to determine the minimum value path in the organization that is the structure of the monitoring system.

Let us specify the question of object $O b$ and the monitoring system. Assume that determining the state of an object $O b$ with a given probability $P_{s}$ requires timely measurement of four groups of quantities. These include production indicators $X 1$ (group "quality-volume of production"), indicators of marketing activities $X 2$ (group "advertising and sales"), indicators of administrative and financial activities $X 3$ (group "state reporting-financial work with banks and others enterprises"), indicators of moral and psychological relations $X 4$ (group "leadership-leadership" and "leadership-performers").

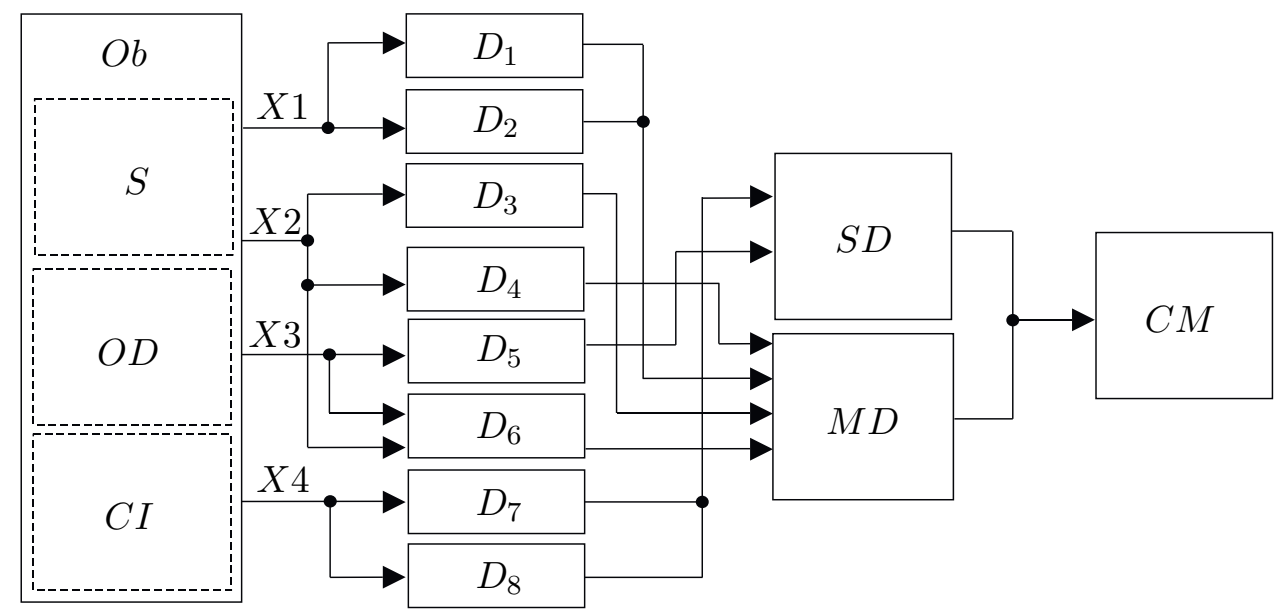

Fig. 3. Monitoring system of object $O b$ (enterprises, organizations) for four groups of parameters.

To determine the current values of each of the groups involved primary information sensors $D_{i}$ witch working with sources of information: with open publications and speeches $S$ ( $D_{1}$ is newspapers, magazines; $D_{2}$ is advertising, price lists; $D_{3}$ is conferences, meetings, etc.), official documentation $O D$ ( $D_{4}$ is reports; $D_{5}$ is official correspondence), confidential information $C I$ ( $D_{6}$ is rumours; $D_{7}$ is official inquiries; $D_{8}$ is informal activities). Such primary sensors can be trained by specialists who receive appropriate information from individual sources about the condition of the object. 
Measurement signals from them are sent through communication channels (mail, telephone, electronic networks, etc.) to the links of information processing and preparation for generalization. Such links may be the security department $S D$ and the marketing department $M D$. Conclusions on materials from the $S D$ and $M D$ departments are carried out by the competitor management $C M$.

Believe that the functional efficiency of communication channels between individual links $\left(D_{i}\right.$ sensors, processing links $S D, M D$ and generalization link $C M$ ) is credited with adjusting the level of perfection of the previous link. This enrolment is performed according to the rule of series-connected elements that is by multiplying the levels of functional perfection of the corresponding link and communication channel.

For the block scheme shown in Fig. 3, the equations of spending rationalization can?t be written. This is due to the structural uncertainty of the sensor $D_{6}$ regarding the efficiency of displaying the parameters $X 2$ and $X 3$, as well as the uncertainty of the functional perfection of the information processing units $S D$ and $M D$ separately for parameters $X 1, X 2, X 3$ and $X 4$. Thus, there is a need to build an equivalent block scheme. It is shown in Fig. 4 To perform numerical calculations will set the state of the monitoring system, Table 2 . Such prior information is required. It is formalized by the involvement of experts and analysis of similar systems.

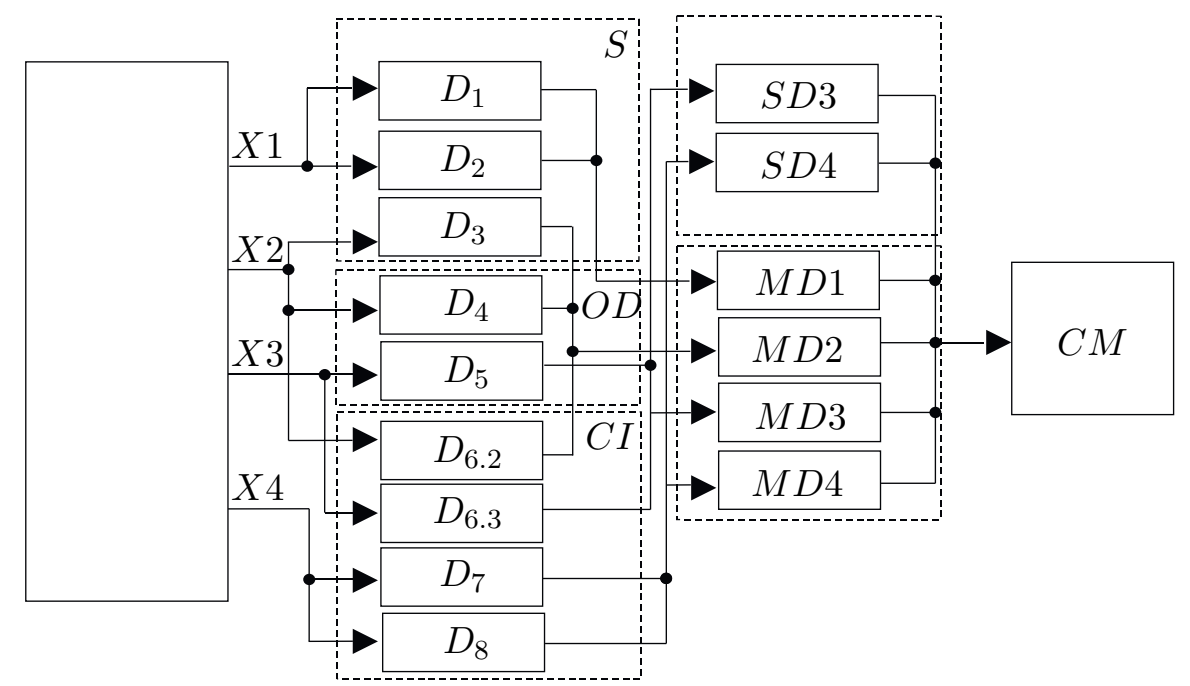

Fig. 4. Equivalent scheme of the object monitoring system for four groups of parameters.

The results are summarized in Table 2. The corresponding graphs show the probabilities of the task $P_{j}$ (levels of perfection) of each link, as well as the values of the approximation coefficients $A_{j}$ for calculations with functions (11). Data from Table 2 take into account the possibility of different efficiency of the links with information from different sources. The number of the link in both cases corresponds to its ordinal value in Fig. 4 if we count the links from top to bottom for their functional purpose.

Data on specific numerical values of $P_{s e n, j}, P_{\text {proc }, k}$ and $P_{g e n}$ are calculated by (7), based on the functional affiliation of the link. Another way to determine them is the statistical processing of the results of the performance their functions by such a link. This is equations and statistical processing data determine the needful and ways to parametrically improve the perfection of each link.

Numerical values for the coefficients $A_{s e n, j}, A_{p r o c, k}$ and $A_{g e n}$ (conventional units) are obtained by expert appointment, experimentally or by the algorithm of pair wise comparison (priority detection). The adjacency matrix [8] in pair wise comparison will be formed horizontally and vertically from the results of expert comparison $A_{i k}$ and $A_{k i}$ :

$$
A_{i k}=\left\{\begin{array}{l}
10, \quad A_{i k}=A_{k i}, \\
15, \quad A_{i k}>A_{k i} \\
5, \quad A_{i k}<A_{k i} .
\end{array} \rightarrow A_{i}=\sum_{k=1}^{k=4} A_{i k}\right.
$$


Table 2. Structural correspondence of the equivalent scheme of the monitoring system.

\begin{tabular}{|c|c|c|c|c|c|c|c|}
\hline Number of links & $P_{\text {sen }, j}$ & $P_{\text {proc }, k}$ & $P_{\text {gen }}$ & Number of links & $A_{\text {sen }, j}$ & $A_{\text {proc }, k}$ & $A_{\text {gen }}$ \\
\hline 1 & 0.85 & 0.75 & 0.99 & 1 & 10 & 30 & 50 \\
\hline 2 & 0.80 & 0.80 & - & 2 & 10 & 25 & - \\
\hline 3 & 0.70 & 0.80 & - & 3 & 20 & 25 & - \\
\hline 4 & 0.75 & 0.75 & - & 4 & 20 & 25 & - \\
\hline 5 & 0.70 & 0.90 & - & 5 & 20 & 40 & - \\
\hline 6 & 0.65 & 0.70 & - & 6 & 25 & 40 & - \\
\hline 7 & 0.80 & - & - & 7 & 25 & - & - \\
\hline 8 & 0.75 & - & - & 8 & 30 & - & - \\
\hline 9 & 0.60 & - & - & 9 & 30 & - & - \\
\hline
\end{tabular}

This equations and statistical processing data determine the degree of necessity and ways of parametric improvement of the functional perfection of each link. Functional-value analysis aims to address three issues. The first is to test the ability of the monitoring system to perform its functional tasks with a given level of excellence. The second issue is to identify the possibility of structural and parametric simplification of the system. The third issue is to find out the cheapest option for structural or parametric adjustment of the system in order to increase its functional perfection.

Consider the approach to solving the first part of the problem. In this case, the set level of perfection of the monitoring system $P_{\Sigma}$ will be considered not less than 0.85 . The monitoring system will effectively functioning if are reached the required levels of probabilities of control $\left(P_{X i}, i=1,2,3,4\right)$ over the values of all four groups of parameters $X i$. They take into account the efficiency of the primary sensors of information, its processing units and the corresponding communication channels. Also it is necessary to take into account the probability $P_{X 5}=P_{g e n}$, which characterizes the perfection of the generalization of the $C M$ and is given in Table 2 as source data. Therefore, the condition for successful operation of the system will be:

$$
P_{\Sigma}=\prod_{i=1}^{5} P_{X i} \geqslant 0.85 .
$$

The values of individual probabilities $P_{X i}$ can be calculated using an equivalent block scheme (Fig. 4) and the rules of generalization when working with serial-parallel connections in block scheme. This takes into account the existing functional tasks assigned to each link and the entire list of existing connections.

The corresponding probabilities will be:

$$
\left\{\begin{array}{l}
P_{X 1}=\left(1-\prod_{j=1}^{2}\left(1-P_{\text {sen }, j}\right)\right) P_{M D 1}, \\
P_{X 2}=\left(1-\prod_{j=3,4,6}\left(1-P_{\text {sen }, j}\right)\right) P_{M D 2}, \\
P_{X 3}=\left(1-\prod_{j=5,6}\left(1-P_{\text {sen }, j}\right)\right)\left(1-\prod_{k=S D 3, M D 3}\left(1-P_{k}\right)\right), \\
P_{X 4}=\left(1-\prod_{j=7,8}\left(1-P_{\text {sen }, j}\right)\right)\left(1-\prod_{k=S D 4, M D 4}\left(1-P_{k}\right)\right) .
\end{array}\right.
$$

The use of (18) will test the ability of the monitoring system to perform its functional tasks.

\section{Results and discussion}

The results of calculations by (18) are given in Table 3 and Fig. 5. Analysis of calculations shows that condition (17) is not fulfilled. Current structure of the monitoring system (Fig. 3) can not perform the task with the required perfection level of 0.85 . 
Data from Table 3 allow drawing preliminary conclusions. First, it is possible to analyse the current

Table 3. Probabilities of determining all measurement groups.

\begin{tabular}{|c|c|c|c|c|c|}
\hline$P_{X 1}$ & $P_{X 2}$ & $P_{X 3}$ & $P_{X 4}$ & $P_{X 5}$ & $P_{\sum}$ \\
\hline 0.77 & 0.72 & 0.91 & 0.84 & 0.99 & 0.42 \\
\hline
\end{tabular}

quality of the components of the system that analysed by characteristics $P_{X i}$. It is clear that the value of the probabilities $P_{X i}$ is not more than 1 . Therefore, the condition of exceeding $P_{\Sigma}$ of a given level can be only if the given level $P_{s}$ exceeds each of the probabilities $P_{X i}$ :

$$
P_{X i} \geqslant P_{s}=0.85, \quad i=\overline{1,5} \text {. }
$$

So, condition (17) is satisfied only by the values $P_{X 3}$ and $P_{X 5}$. Second, it is possible to choose a strategy to improve the system. For example, it is most necessary to increase the values of the probabilities $P_{X 1}$ and $P_{X 2}$. It is needful to choose the path of value-effective increase of probability: parametric improvement of separate links or introduction of additional parallel connected links. Also it is useful to preliminary calculation of the probabilities $P_{X i}$ and their verification with (19).

It is possible to approximate probability value $P_{X i, o p}$. Assuming that the value of functional improvement according to the criteria $P_{X i}$ is approximately the same for all five links, the following statement will be:

$$
P_{X 1}=P_{X 2}=\ldots=P_{X i}=\ldots=P_{X n}, \quad i=\overline{1, n} .
$$

The value of $P_{X i, o p}$ will be:

$$
P_{X i, o p}=\sqrt[n]{P_{s}} \approx P_{X i}
$$

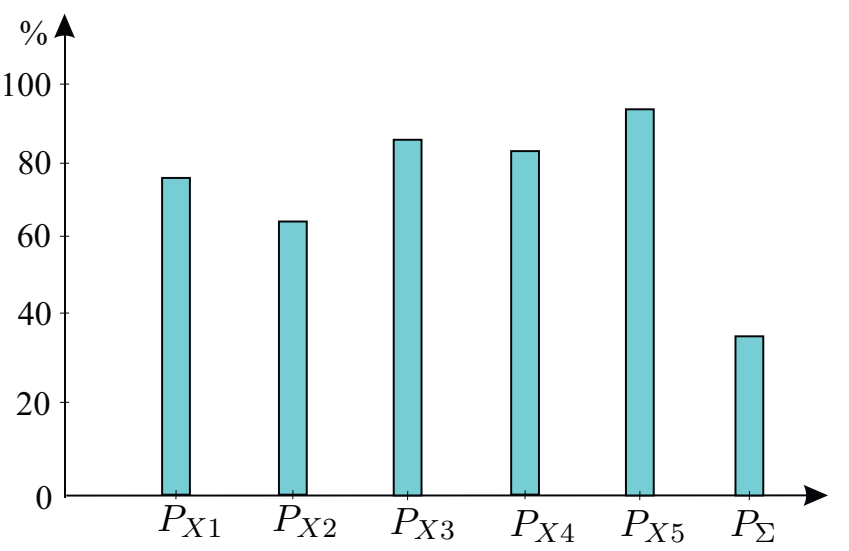

Fig. 5. Distribution of levels of individual groups.

For the system under consideration $P_{X i, o p}=$ $\sqrt[5]{P_{s}}=\sqrt[5]{0.85}=0.96 \approx P_{X i}$. Analysis shows that all four probabilities $P_{X i}$ are subject to increase, but probabilities $P_{X 1}, P_{X 2}$ and $P_{X 4}$ are subject to unconditional increase.

In addition, each series-connected subsystem of a complex system not only increases the value in advance, but also reduces its functional perfection. As a result, the more subsystems connected in series in a complex system, the higher the requirements for the level of perfection of them.

The second part of the task is to test the possibility of structural simplification of the system, which will reduce its value. In this case, such a possibility will be absent, because the analysis showed insufficient efficiency of the existing system. This requires its further complication. It conclusion will be correct if the functional necessity of each of the series-connected subsystems is confirmed.

It remains to consider the features of the third part of the task. Its content is in the proposal of the cheapest and value-effective option of restructuring the system which will ensure condition (17). That is, it is necessary to determine both structural and parametric areas of improvement of the monitoring system. The initial information for the analysis will be the functional affiliation of the system, the specified level of its functional perfection and the data of Table 2. Value indicators at this stage of paper are not considered.

There are three alternative ways to achieve this aim. The first of them is to provide a rational distribution of requirements for the levels of functional excellence of individual units without structural changes in a complex system. In this case, it is necessary to look for ways to parametrically improve each individual link in order to achieve a rationally defined level of functional perfection. The distribution of the required levels of functional perfection of all individual units is determined in the process of value rationalization in solving systems by (15) and (17). 
The second approach is based only on structural adjustments of a complex system without interfering without changes in the efficiency of individual units. Its implementation involves the introduction of additional links (sensors, processing links and communication channels) in the block diagram of the system.

A third direction combines the two previous directions. It involves to minimalist (rationalize) of the system due to the most effective changes in the internal structure of the links and improvement the system. This direction can be called structural-parametric.

To solve the problem due to the rational distribution of requirements for the levels of functional perfection of individual units must be used (15). The structure of the monitoring system will not change. The levels of functional excellence must be further confirmed by changing the values of the parameters of the subsystems.

Thus, this is a value-parametric optimization or rationalization (depending on the accuracy of research) of the monitoring system. The content of such adjustment is in the corresponding change of parameters of separate subsystems due to internal qualitative and quantitative changes within each subsystem. Structural-parametric rationalization is more flexible in achieving the end result.

\section{Conclusions}

The method of functional-value modeling of a complex system with a mixed combination of its subsystems is improved. It allows parametric control of the functional perfection of a complex system under the condition of its minimum value. This method is adapted for use at different levels of a priori uncertainty of the original data and can be used at all stages of the existence of a complex system: development, operation and disposal. It is useful for the study of weakly formalized and informalized complex systems, that is allows quality analysis of a complex system to be translated into quantitative.

The initial data for calculations by the advanced method consist of determining the functional purpose of each subsystem, its structural connections with other subsystems and structure of equivalent schemes. The introduction of analytical approximation allows the improvement of a complex system under the condition of the minimum value. The developed order of structural functional-value calculations of a complex system with mixed combination of subsystems allowed obtaining equations of its value rationalization. The solution of such system is based on the method of Lagrange multipliers and involvement of an iterative approach in solving equations above the third order.

The analysis of the peculiarities of the use of functional-value analysis of a complex system with a mixed combination of subsystems has been done. It allowed checking the possibility of the system monitoring its functional tasks with a given level of perfection. Also it identifies opportunities for structural and parametric simplification of the system and finds out the cheapest option of structural and parametric restructuring of the system. This allows you to predict the value behaviour of a complex system with a mixed combination of subsystems under the condition of performing functional tasks.

The application of the advanced method contributes to the solution of direct and inverse problems of rationalization of the structure of complex systems with a mixed combination of subsystems. It allows determining the required number of sensor subsystems and information processing from them, which satisfies a given level of system excellence and has a minimum value. In addition, it allows choosing the structure of the system in relation to the configuration of sensors and processing subsystems. This satisfies a given level of perfection (quality) and has a minimum value.

[1] Good H., Machol R. System Engineering. An introduction to the design of large-scale systems. McGrawHill Book Company, New York (1957).

[2] Glushkov V. Introduction to cybernetics. USSR Academy of Sciences, Kyiv (1964), (in Russian).

Mathematical Modeling and Computing, Vol. 8, No. 2, pp. 215-227 (2021) 
[3] Jaehyun L., Jinko K., Woong K. Day-Ahead Electric Load Forecasting for the Residential Building with a Small-Size Dataset Based on a Self-Organizing Map and a Stacking Ensemble Learning Method. Applied Sciences. 9 (6), 1231 (2018).

[4] Senyel M. A., Guldmann J.-M. Joint Values in Electricity and Natural Gas Distribution Infrastructures: The Role of Urban Factors. Urban Science. 2 (2), 35 (2018).

[5] Beavers D., Stamey J. Bayesian sample size determination for value-effectiveness studies with censored data. PLoS ONE. 13 (1), e0190422 (2018).

[6] Ruyi L., Zhen W. Advances in Difference Equation. PLoS ONE. 1, 1-12 (2018).

[7] Sentz K., Ferson S. Combination of Evidence in Dempster-Shafer Theory. United States: N. p. (2002).

[8] Saaty T. The U.S.-OPEC energy conflict: the payoff matrix by the analytic hierarchy process. International Journal of Game Theory. 8, 225-234 (1979).

[9] Pelin A., Munteanu V., Pantea M., Gligor D. Methodological approaches in realizing and applying valuebenefit analysis for the investment projects. Annals of the University of Oradea. Economic Science. 2, 156-162 (2009).

[10] Babichev S., Osypenko V., Lytvynenko V., Voronenko M., Korobchynskyi M. Comparison analysis of biclustering algorithms with the use of artificial data and gene expression profiles. Eastern-European Journal of Enterprise Technologies. 91, 19-32 (2018).

[11] Elrehim M., Eid M., Sayed M. Structural optimization of concrete arch bridges using Genetic Algorithms. Ain Shams Engineering Journal. 10 (3), 507-516 (2019).

[12] Leachtenauer J. Resolution requirements and the johnson criteria revisited. Infrared Imaging Systems: Design, Analysis, Modeling, and Testing XIV. 5076, 1-15 (2003).

[13] Korobchynskyi M., Slonov M., Mariliv A., Mieshkov S. Method for determining the rational time intervals for detecting objects by thermal imager. 2018 IEEE Second International Conference on Data Stream Mining \& Processing (DSMP). 494-497 (2018).

[14] Slonov M. Functional-Cost Approach to Structural Improvement of Complex System: Educational Process. Notes of V.I. Vernadsky Taurida National University. 69, 124-128 (2019).

[15] Korobchynskyi M., Slonov M., Rudenko M., Maryliv O. Method of structural functional-value modeling of a complex hierarchic system. Shpringer, Advances in Intelligent Systems and Computing. 213-231 (2021).

[16] Bertsekas D. Constrained Optimization and Lagrange Multiplier Methods. Athena, Athena Scientific (1982). 


\title{
Метод функціонально-вартісного моделювання складних систем зі змішаним сполученням підсистем
}

\author{
Коробчинський M. ${ }^{1}$, Слонов M. ${ }^{1}$, Марилів O. ${ }^{1}$, Лисенко С. ${ }^{1}$, Легомінова С. ${ }^{2}$, Литвинська С. ${ }^{3}$ \\ ${ }^{1}$ Воєнно-дипломатична академія імені Євгенія Березняка, \\ вул. Юрія Ілленка, 81, 04050, Київ, Україна \\ 2 Державний університет телекомунікаиій, \\ вул. Солом'янсъка, 7, 03680, Київ, Украӥна \\ ${ }^{3}$ Національний авіаційний університет, \\ nросп. Комарова, 1, 02000, Київ, Україна
}

\begin{abstract}
Запропонований удосконалений метод функціонально-вартісного аналізу складної системи зі змішаним сполученням підсистем при аналітичній апроксимації залежності їх вартості від рівня функціональної досконалості. Мінімізацію вартості складної системи за умовою виконання нею свого функціонального призначення на заданому рівні запропоновано проводити методом множників Лагранжа. Застосування розробленого методу дозволяе перевірити можливість виконання системою моніторингу своїх функціональних завдань із заданим рівнем досконалості. Даний метод адаптований до застосування для різних рівнів апріорної невизначеності вихідних даних та може бути корисним на всіх етапах існування складної системи: розробки, експлуатації та утилізації. Крім того, він може бути використаним для дослідження слабоформалізованих та неформалізованих складних систем.
\end{abstract}

Ключові слова: складні системи, досконалість складної системи, апроксимуючі функцї. 